\title{
As competências da psicopedagogia nos processos de ensino- aprendizagem
}

\section{The competences of psychopedagogy in teaching-learning processes}

\author{
DOI: $10.46814 /$ lajdv2n2-001
}

Recebimento dos originais: 01/02/2020

Aceitação para publicação: 10/02/2020

\section{Jaciara Xavier Pereira Ribeiro}

Doutoranda em Ciências da Educação pela Instituição Brasil de Educação e Pesquisa - IBEP, em parceria com a Universidade Nacional de La Plata e Universidade Del Sol

Instituição: Instituição Brasil de Educação e Pesquisa - IBEP, em parceria com a Universidade Nacional de La Plata e Universidade Del Sol - UNADES/IBEP/BRASIL

Endereço: UNADES - 14 De Mayo 462, Asunción, Paraguai/ IBEP - sede no Calçadão Arthur Bernardes, $n^{\circ}$ 152, Sala 06, Bairro Centro, Viçosa - MG - CEP 36.570- 061

E-mail: jaciaraxp@yahoo.com.br

\section{RESUMO}

A Psicopedagogia é um campo de estudo recentes, principalmente no Brasil tendo como desafio a construção da identidade do Psicopedagogo seu campo de atuação, vivenciados no cotidiano do processo de ensino- aprendizagem. Sendo assim, para a definição do problema de pesquisa levou-se em consideração a expectativa de investigar a importância da Psicopedagogia nos processos de EnsinoAprendizagem. Tendo como objetivo geral: Apresentar conceitos importantes na área da Psicopedagogia nos processos de Ensino-aprendizagem e os objetivos específicos são: descrever conceitos sobre a Psicopedagogia; apresentar o profissional Psicopedagogo e por fim descrever a Psicopedagogia como uma junção da Pedagogia, Psicologia e outras ciências. Os objetivos foram alcançados, respondendo à questão problema. Como limitação do artigo, a metodologia utilizada para pesquisa foi feita apenas revisão documental e bibliográfica, neste sentido, sugere-se a realização de novas pesquisas, desta vez de forma quantitativa ou qualitativa em ambientes escolares e também em Instituições financeiras, a exemplo das Cooperativas de Crédito, avaliando a importância da Psicopedagogia nos processos de seleção, recrutamento e integração do contratado e na gestão do conhecimento dos profissionais, na busca pelo eficiência e eficácia da organização no mercado de atuação.

Palavras-chave: Psicopedagogia, Psicopedagogo, Pedagogia e Psicologia.

\begin{abstract}
Psychopedagogy is a recent field of study, mainly in Brazil, with the challenge of building the identity of the Psychopedagogue its field of action, experienced in the daily teaching-learning process. Thus, in order to define the research problem, the expectation of investigating the importance of Psychopedagogy in the Teaching-Learning processes was taken into account. Having as general objective: To present important concepts in the area of Psychopedagogy in the teaching-learning processes and the specific objectives are: to describe concepts about Psychopedagogy; present the professional Psicopedagogo and finally describe the Psychopedagogy as a combination of Pedagogy, Psychology and other sciences. The objectives were achieved, answering the problem question. As a limitation of the article, the methodology used for research was made only documentary and bibliographic review, in this sense, it is suggested to carry out new research, this time in a quantitative or qualitative way in school environments and also in financial institutions, such as the Cooperatives of Credit, evaluating the importance of Psychopedagogy in the
\end{abstract}


selection, recruitment and integration processes of the contractor and in the management of the professionals' knowledge, in the search for efficiency and effectiveness of the organization in the market.

Keywords: Psychopedagogy, Psychopedagogue, Pedagogy and Psychology

\section{INTRODUÇÃO}

A Psicopedagogia é um campo de estudo recentes, principalmente no Brasil tendo como desafio a construção da identidade do Psicopedagogo seu campo de atuação, vivenciados no cotidiano do processo de ensino- aprendizagem, propondo especialmente alternativas didático-metodológicas que visem contribuir para a redução dos altos índices de fracasso escolar e exclusão social, de forma a se tornar um profissional respeitado pelas instituições, para desenvolvimento do conhecimento.

$\mathrm{O}$ artigo trata sobre a Psicopedagogia que é uma área que estuda e lida com o processo de aprendizagem e com os problemas dele decorrentes, recorrendo aos conhecimentos de várias ciências, sem perder de vista o fato educativo, nas suas articulações sociais mais amplas (SCOZ, 1994, p.12).

A história da psicopedagogia tem início na Europa, em 1946, onde foram fundados os primeiros centros psicopedagógicos por J. Boutonier e George Mauco, com direção médica e pedagógica. Unindo conhecimentos da área de Psicologia, Psicanálise e Pedagogia, esses centros tentavam readaptar crianças com comportamentos socialmente inadequados na escola ou no lar e atender crianças com dificuldades de aprendizagem apesar de serem inteligentes (BOSSA, 2000, p. 39).

Weiss (2001) ressalta, em seus estudos, que a Psicopedagogia é um caminho fundamental à ampliação das possibilidades de busca de qualidade nos processos relacionais, presentes na aprendizagem humana, que ocorre no movimento do desejo, potencialidade maior de cada um de nós, enquanto sujeitos humanos, de melhor construirmos nossas próprias aprendizagens.

O psicopedagogo, no papel de agente corretor, de acordo com Visca (1987), deve priorizar o "conhecimento" do paciente, mesmo que para tal, tenha de realizar encaminhamentos a outros profissionais. O psicopedagogo deverá ter um embasamento teórico para o desenvolvimento de sua função (PERES, OLIVEIRA, 2007).

(...) o objeto de estudo da Psicopedagogia deve ser entendido a partir de dois enfoques: preventivo e terapêutico. O enfoque considera o objeto de estudo da Psicopedagogia o ser humano em desenvolvimento, enquanto educável. Seu objeto de estudo é a pessoa a ser educada, seus processos de desenvolvimento e as alterações de tais processos. Focaliza as possibilidades do aprender, num sentido amplo. Não deve se restringir a uma só agência como a escola, mas ir também à família e à comunidade. Poderá esclarecer, de forma mais ou menos sistemática, a professores, pais e administradores sobre as características das diferentes etapas do desenvolvimento, sobre o progresso nos processos de aprendizagem, sobre as condições psicodinâmicas da aprendizagem, sobre as condições determinantes de 
dificuldades de aprendizagem. O enfoque terapêutico considera o objeto de estudo da psicopedagogia a identificação, análise, elaboração de uma metodologia de diagnóstico e tratamento das dificuldades de aprendizagem (GOLBERT apud BOSSA, 2000, p. 20).

A Psicopedagogia inicialmente foi utilizada como adjetivo, indicando uma forma de atuação que apontava a inevitável interseção dos campos do conhecimento da Psicologia e da Pedagogia (PORTO, 2009).

Sendo assim, para a definição do problema de pesquisa levou-se em consideração a expectativa de investigar a importância da Psicopedagogia nos processos de Ensino-Aprendizagema. O problema é expresso, então, pela questão: quais as competências da Psicopedagogia nos processos de EnsinoAprendizagem? Tendo como objetivo geral: Apresentar conceitos importantes na área da Psicopedagogia nos processos de Ensino-aprendizagem e os objetivos específicos são: descrever conceitos sobre a Psicopedagogia; apresentar o profissional Psicopedagogo e por fim descrever a Psicopedagogia como uma junção da Pedagogia, Psicologia e outras ciências.

Vergara (2005, p.32) aborda que o autor de um estudo o justifica ao atribuir-lhe contribuições de ordem prática ou ao estado da arte na área. Neste sentido o presente trabalho poderá trazer como contribuição prática, o conhecimento sobre a Psicopedagogia.

A METODOLOGIA utilizada quanto aos meios de investigação, para a realização deste estudo, tornou-se necessário o desenvolvimento de uma pesquisa documental e de caráter bibliográfica, conceituando termos relacionados aos conceitos gerais sobre Psicopedagogia.

Este artigo está estruturado em capítulos, incluindo a introdução, na qual se apresenta o problema de pesquisa, os objetivos, a justificativa, metodologia e a estrutura do artigo. Os demais capítulos organizam-se da seguinte maneira: no segundo aborda-se sobre conceitos sobre a psicopedagogia, Psicopedagogia como uma junção da Pedagogia, Psicologia e outras ciências; no terceiro formulam-se as conclusões, acrescidas das limitações e sugestões para novos estudos, e por fim são apresentadas as referências bibliográficas.

\section{PSICOPEDAGOGIA}

A Psicopedagogia é um campo de estudo recentes, principalmente no Brasil tendo como desafio a construção da identidade do Psicopedagogo seu campo de atuação, vivenciados no cotidiano do processo de ensino- aprendizagem, propondo especialmente alternativas didático-metodológicas que visem contribuir para a redução dos altos índices de fracasso escolar e exclusão social, de forma a se tornar um profissional respeitado pelas instituições, para desenvolvimento do conhecimento.

Aranha (2000), que menciona o principal valor que permeia, portanto, a ideia da inclusão é o configurado no princípio da igualdade, pilar fundamental de uma sociedade democrática e justa: a 
diversidade requer a peculiaridade de tratamentos, para que não se transforme em desigualdade social. A Psicopedagogia contribui para inclusão social, por visar solucionar os problemas no indivíduo que necessita de apoio.

A Psicopedagogia se apresenta com um caráter multidisciplinar devido à complexidade dos problemas de aprendizagem, que busca conhecimento em diversas outras áreas do conhecimento, além da psicologia e da pedagogia. Lidar com o insucesso escolar, com o baixo rendimento, com as múltiplas implicações para a autoavaliação da criança, para a família, professores e comunidade constitui-se em tarefa complexa e desafiadora para a qual não se tem ainda uma resposta acabada e pronta, o que aponta para a necessidade de buscar alternativas que possam minimizar tal situação (OKANO et al, 2003).

Alicia Fernández (2001) destaca que é preciso, no campo psicopedagógico, sempre incorporar novos saberes e conhecimentos sobre a inteligência, o corpo, o desejo e o organismo pelo fato de que estes são os principais níveis imbricados no ato humano de aprender: cada sujeito, em seus processos, possui sua própria modalidade de aprendizagem, o que quer dizer que cada um, em sua individualidade, possui suas próprias condições, seus limites e meios para acessar conhecimentos e construir saberes. No que diz respeito ao produzir conhecimento em Psicopedagogia, é também importante ampliar o ambiente e a atuação daquele profissional que pesquisa: de modo geral, é preciso perceber que a pesquisa só pode ser considerada centro de seu aspecto educativo, ou seja, da própria formação do psicopedagogo.

Para obtermos algum domínio de nossos processos de autoria de pensamento, é de extrema valia conquistar e exercitar a qualidade de sermos produtivos, conscientes e emancipados, tornando-nos sujeitos capazes de encontrar nossos próprios espaços e tempos, e sermos desejantes de crescimento, recusando-nos cotidianamente a sermos apenas objetos, a sermos apenas meros expectadores de todo este movimento.

O saber psicopedagógico se obtém a partir de duas vertentes: da experiência, "mergulhando na tarefa", e através do tratamento psicopedagógico didático. Posicionando-se como observador ou como juiz é muito difícil contatar com o saber. Um espaço importante de gestação do saber psicopedagógico é o trabalho de autoanálise das próprias dificuldades e possibilidades no aprender, pois a formação do psicopedagogo, assim como requer a transmissão de conhecimentos e teorias, também requer um espaço para a construção de um olhar e uma escuta psicopedagógicos a partir de uma análise de seu próprio aprender.

Dentro dessa conotação adjetiva da psicopedagogia, alguns autores, principalmente pertencentes ao campo pedagógico, no final da década de 70 e início dos anos 80 no Brasil, chamaram de "atitude psicopedagógica" o que em verdade era um "psicologismo radical". Por isso, tratavam de denunciar a formação dos professores por eles cognominada de psicopedagogia (BOSSA, 2000). 
Posteriormente, a Psicopedagogia assumiu uma conotação substantiva, o que, por um lado, correspondeu a uma aplicação conceitual e, por outro, causou um lamentável estado de confusão, por causa da utilização de toda uma polissemia aplicada a um só termo. Assim, em relação à questão conceitual, mencionando a confusão que se apresenta, creio que essa ambiguidade ou dubiedade se estende também à prática (PORTO, 2009).

Se a (in)definição do termo Psicopedagogia produz um estado de confusão conforme aponta Neves, vejamos a definição do objeto de estudo da Psicopedagogia segundo alguns psicopedagogos brasileiros.

(...) o objeto central de estudo da Psicopedagogia está se estruturando em torno do processo de aprendizagem humana: seus padrões evolutivos normais epatológicos - bem como a influência do meio (família, escola, sociedade) no seu desenvolvimento (KIGUEL apud BOSSA, 2000, p. 19).

(...) a psicopedagogia estuda o ato de aprender e ensinar, levando sempre em conta as realidades interna e externa da aprendizagem, tomadas em conjunto. E, mais, procurando estudar a construção do conhecimento em toda a sua complexidade, procurando colocar em pé de igualdade os aspectos cognitivos, afetivos e sociais que lhe estão implícitos (NEVES apud BOSSA, 2000, p. 19).

(...) a psicopedagogia estuda o processo de aprendizagem e suas dificuldades e, em uma ação profissional, deve englobar vários campos do conhecimento, integrando-os e sintetizando-os (SCOZ apud BOSSA, 2000, p. 19)

Essas considerações em relação ao objeto de estudo da Psicopedagogia sugerem que há um certo consenso quanto ao fato de que ela deve ocupar-se em estudar a aprendizagem humana, porém é uma ilusão pensar que tal consenso nos conduza, a todos, a um único caminho. O tema da aprendizagem apresenta tamanha complexidade que tem a dimensão da própria natureza humana e caberia um outro ensaio para tratá-lo. É importante, no entanto, ressaltar que a concepção de aprendizagem é resultado de uma visão de homem, e é em razão desta que acontece a práxis psicopedagógica (PORTO, 2009).

$\mathrm{O}$ assessoramento psicopedagógico nas escolas baseia-se, em boa medida, em responder a demandas. Um docente, uma equipe educacional, um diretor, etc., formulam uma demanda, que gera um processo no qual o assessor terá um papel relevante. A demanda refere-se a problemas que precisam ser resolvidos, situações suscetíveis de modificar, temas que devem ser trabalhados ou conflitos a solucionar (BONALS; GONZÁLEZ, 2008).

Em um âmbito muito geral, teríamos de situar a demanda de assessoramento e orientação psicopedagógica em um contexto histórico recente no mundo da educação, onde se aposta em um modelo inclusivo, no qual o ensino se ajusta às diferentes necessidades educacionais dos alunos, ao mesmo tempo em que são considerados os interesses e as necessidades dos docentes. Há menos de três décadas o 
assessoramento psicopedagógico foi introduzido nas escolas de modo generalizado e com uma força surpreendente (BONALS; GONZÁLEZ, 2008).

Uma parte importante da contribuição psicopedagógica à educação atual é dada como resposta às demandas que recebemos das escolas. Eis uma razão a mais para que essas respostas se fundamentem em profunda compreensão do que as gera e evitem a precipitação ou a ingenuidade das ações originadas de pouca reflexão. A análise de cada uma dessas demandas de intervenção deve servir igualmente para diferenciar as atuações convenientes daquelas que não podemos nos permitir sem redefini-las previamente (BONALS; GONZÁLEZ, 2008).

A Psicopedagogia como uma área de estudo interdisciplinar está integrada por diversas ciências, como pedagógica, psicológica, fonoaudiológica, entre outras, sempre a serviço do desenvolvimento do processo de ensino e aprendizagem.

A psicopedagogia apresenta modalidades de atuação como a clínica e a institucional. A intervenção clínica é a mais antiga e surgiu na fronteira entre a psicologia e a pedagogia, privilegiando o atendimento individual de forma terapêutica. Assim, vemos as escolas encaminhando o aluno com dificuldades de aprendizagem para as clínicas. Estas clínicas geralmente trabalham com uma equipe interdisciplinar composta por Psicopedagogo, psicólogos, fonoaudiólogos, médicos, entre outros, que após o diagnóstico do problema, iniciam o tratamento.

A intervenção institucional é mais recente. Ela geralmente é desenvolvida na própria escola com o objetivo de prevenir ou superar as possíveis dificuldades de aprendizagem.

Desta forma, a Psicopedagogia tem procurado contribuir para a conscientização da importância do ato educativo, através de uma prática transformadora, visando especialmente o sucesso do aluno e a melhoria na qualidade do processo de ensino e aprendizagem (OLIVEIRA, 2001).

Morais (2004) considera a Psicopedagogia Institucional um modelo teórico-prático que permite um questionamento, um diagnóstico e uma elaboração de recursos para a solução de problemas em situações de carência, conflito, crise, em instituições educacionais.

A Psicopedagogia Institucional contemporânea é reflexo do desenvolvimento do Movimento Institucionalista, que se estendeu para além do campo da Psicologia, e passou a se configurar, na área educacional, como uma busca de compreensão das relações instituídas entre os atores de um mesmo cenário - a Educação.

O termo Psicopedagogia apresenta-se, hoje, com uma característica especial. Quanto mais tentamos elucidá-Io, menos claro ele nos parece. À primeira vista, o termo sugere tratar-se de uma aplicação da Psicologia à Pedagogia, porém tal definição não reflete o significado que esse termo assume em razão do seu nascimento (PORTO, 2009). 
Jorge Visca (1987) compreendeu a Psicopedagogia como uma possibilidade de termos uma visão mais ampliada dos complexos processos que nos levam à efetiva aprendizagem.

\subsection{O PSICOPEDAGOGO}

A profissão do psicopedagogo não está regulamentada, mas o projeto se encontra na Comissão de Constituição, Justiça e Redação, na Câmara dos Deputados Federais, para ser aprovada e tem sido oferecido por instituições devidamente autorizadas ou credenciadas, porém tem sido a dificuldade dos psicopedagogos em propor procedimentos de avaliação e de intervenção.

Carvalho (2011) pensa ser imperativo buscar sempre uma supervisão junto a psicopedagogos quanto aos tipos de avaliação do processo de aprendizagem e das dificuldades de aprendizagem que competem ao psicopedagogo. Vale lembrar que na área da Psicopedagogia a relevância do trabalho realizado dependerá da consciência profissional de cada um que nela atua.

Na concepção de Carvalho (2011), as dificuldades muitas vezes são de fatores externos (ambiental), ou seja, estereótipos criados pela família e também pela escola/professores. Portanto, os Psicopedagogos precisam conhecer a causa das dificuldades para encontrar meios de ajudar o aluno e não para excluí-lo.

Nas instituições, o psicopedagogo cumpre a importante função de socializar os conhecimentos disponíveis, promover o desenvolvimento cognitivo e a construção de normas de conduta inseridas num mais amplo projeto social, procurando afastar, contrabalançar a necessidade de repressão. Peres e Oliveira (2007) fazem menção com respeito à importância da prevenção e da intervenção psicopedagógica, mas enfatizam também que não podemos ignorar a fase que precede a essas ações. A etapa de avaliar, por exemplo, a avaliação psicopedagógica, deverá anteceder a toda e qualquer proposta de intervenção, seja ela clínica ou institucional.

De acordo com Chamat (2008), seu papel é de focalizar a problemática dentro do contexto causa/sintoma e atuar sobre eles. Deve planejar sua atuação desde o contato telefônico. Este, muitas vezes, fornece dados de como estão as relações vinculares familiares.

Segundo Chamat (1996), após realizar todo o diagnóstico psicopedagógico, o psicopedagogo estará de posse do quadro "patológico" sobre o caso em estudo, bem como de um sistema de hipóteses que lhe permita direcionar o tratamento psicopedagógico.

O psicopedagogo, conforme Visca (1987), deve estar acessível às chamadas da escola e dar as devidas orientações. No aspecto assistencial, discute-se a necessidade de poder contar com um assistente social, em um trabalho em conjunto. Este levantará as dificuldades e orientará de forma ampla e realista, abrangendo outros aspectos que a família não percebe, mas estão relacionados com a produtividade escolar da criança. 
Os quadros abaixo apresentam situações vivenciadas pelo Psicopedagogo nos diversos campos de atuação.

\begin{tabular}{|c|c|c|c|}
\hline & CLINICOO & INSTITUCIONAL & TEÓRICO \\
\hline DIAGNÓSTICO & $\begin{array}{l}\text { Compreensăo diagnóstica } \\
\text { do sistema de dificuldade } \\
\text { de aprendizagem através } \\
\text { de técnicas especificas e } \\
\text { da integraçäo de dados de } \\
\text { outros exames: } \\
\text { neurológicos, psicológicos, } \\
\text { etc. }\end{array}$ & $\begin{array}{l}\text { Identificar os obstáculos } \\
\text { do desenvolvimento do } \\
\text { processo } \\
\text { aprendizagem através de } \\
\text { técnicas específicas de } \\
\text { análise. institucional e } \\
\text { pedagógica. }\end{array}$ & $\begin{array}{l}\text {-Análise do discurso: } \\
\text {-Análise de atitudes: de } \\
\text {-Codificaçäo } \\
\text { sintomas: } \\
\text {-Psicossomática da } \\
\text { aprendizagem; } \\
\text {-Avaliaçäo } \\
\text { intervençöes, } \\
\text { determinaçäo } \\
\text { variáveis. } \\
\text { Reavaliação constante } \\
\text { dos itens acima. }\end{array}$ \\
\hline $\begin{array}{l}\text { TRATAMENTO E } \\
\text { ASSESSORIA }\end{array}$ & $\begin{array}{l}\text { Familiar em relação ao } \\
\text { processo de aprendizagem. } \\
\text { Orientaçäo junto à escola, } \\
\text { de aspectos evidenciados } \\
\text { no diagnóstico e/ou } \\
\text { tratamento. }\end{array}$ & $\begin{array}{l}\text { Fragmentação } \\
\text { conhecimentos. de } \\
\text { Informação sobre atitudes } \\
\text { pedagógicas om } \\
\text { dificuldades de } \\
\text { elaboração a todos os } \\
\text { níveis. } \\
\text { Implantação de recursos } \\
\text { preventivos. }\end{array}$ & \\
\hline INVESTIGAÇÄO & $\begin{array}{l}\text { Métodos clínicos: } \\
\text {-Trabalho com hipótese; } \\
\text {-Processamento clínico da } \\
\text { entrevista: } \\
\text {-Seleção de amostras: } \\
\text {-Tratamento estatístico } \\
\text { (optativo): } \\
\text {-Supervisão. }\end{array}$ & $\begin{array}{l}\text { Diferentes metodologias: } \\
\text { a)sócio-pedagógica, } \\
\text { histórica antropológica e } \\
\text { etnológica-educativa: } \\
\text { b)Estatístico analítica do } \\
\text { campo de atuaçảo. } \\
\text { Sugestöes de temas para } \\
\text { pesquisa: } \\
\text { da imagem que o } \\
\text { professor tem do aluno e } \\
\text { vice-versa. } \\
\text { sobre a ideologia da } \\
\text { realidade (mitos. } \\
\text { símbolos, etc). }\end{array}$ & \\
\hline
\end{tabular}

Fonte: Revista Psicopedagogia $n^{\circ} 14$ (32): 21-27, 1995 


\begin{tabular}{|c|c|c|}
\hline PROFESSOR & $\begin{array}{l}\text { PSICOPEDAGOGO } \\
\text { IN STITUCIONAL }\end{array}$ & PSICOPEDAGOGO CLINICO \\
\hline 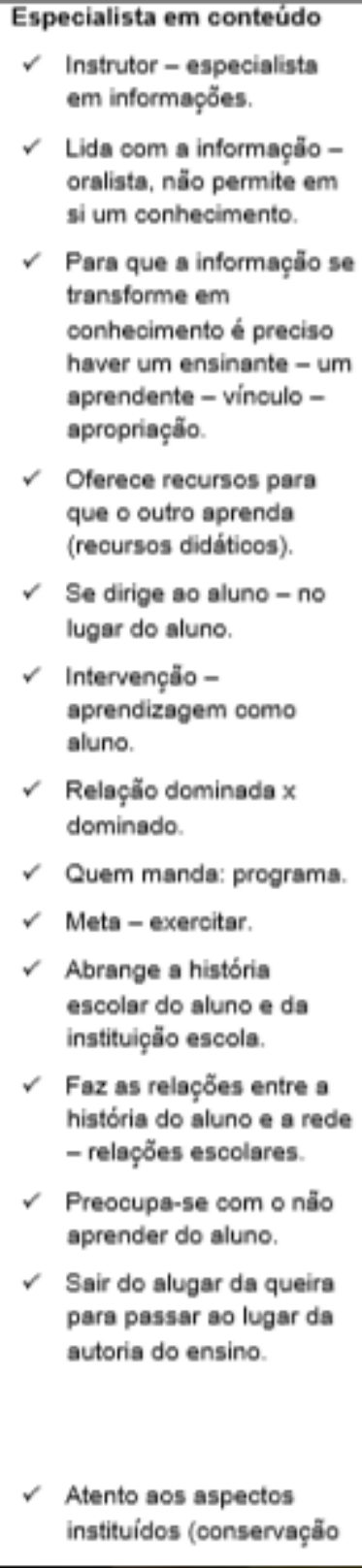 & 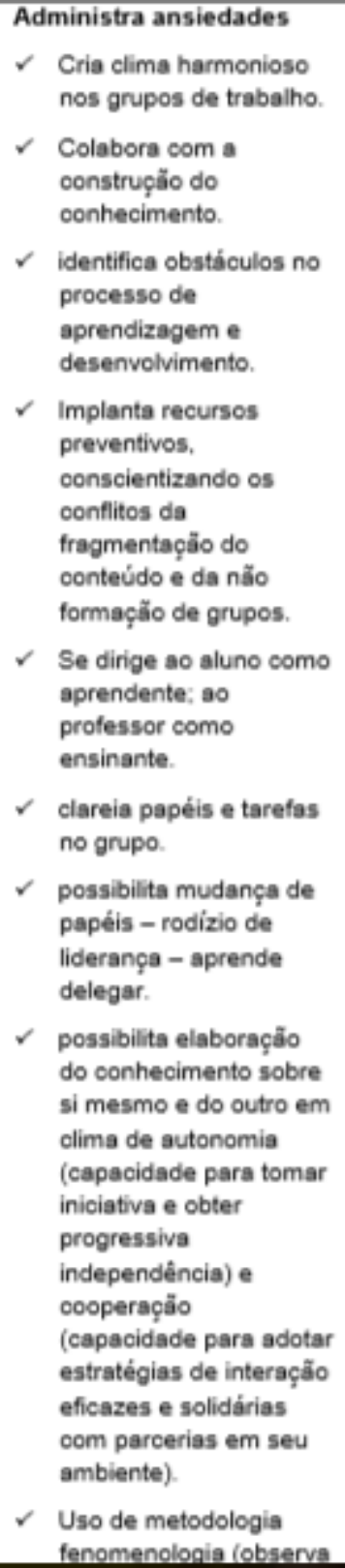 & $\begin{array}{l}\text { Reelabora o processo de } \\
\text { aprendizagem } \\
\checkmark \text { Propicia a construção } \\
\text { do saber. } \\
\text { Devolve ao sujeito o } \\
\text { prazer de aprender. } \\
\text { Quem manda - o } \\
\text { paciente. } \\
\checkmark \text { Pp- testemunha } \\
\text { 'insight. } \\
\text { Resgate da } \\
\text { autonomia. } \\
\checkmark \text { Cardápio individual - } \\
\text { flexivel. } \\
\checkmark \text { Há folga para trabalhar } \\
\text { o desejo. } \\
\checkmark \text { Espaço para rastrear } \\
\text { meta. } \\
\checkmark \text { Objetivo - dirigido à } \\
\text { história do sujeito - } \\
\text { rede de situaçöes } \\
\text { familiares. } \\
\text { Uso de metodologia } \\
\text { clínica. } \\
\checkmark \text { Está dirigida à história } \\
\text { do sujeito porque a } \\
\text { demanda é a cura. } \\
\text { Sintoma: doença? - } \\
\text { tentativa de sair da } \\
\text { armadilha familiar. } \\
\text { Cura: } \\
\text { desaparecimento do } \\
\text { sintoma e apropriaçäo } \\
\text { do saber. }\end{array}$ \\
\hline
\end{tabular}


Todo o trabalho do assistente social deve ser comunicado ao psicopedagogo ou terapeuta. O atendimento psicopedagógico, mediante um olhar clínico, pretende facilitar o diagnóstico da dinâmica relacional e da aprendizagem, a fim de propiciar mudanças e facilitar o trabalho preventivo, objetivando evitar e/ou superar problemas de aprendizagem na relação aluno -"conhecimento"- professor.

\subsection{A PSICOPEDAGOGIA COMO UMA JUNÇÃO DA PEDAGOGIA, PSICOLOGIA E OUTRAS CIÊNCIAS}

Historicamente, a Psicopedagogia surgiu na fronteira entre a Pedagogia e a Psicologia, a partir das necessidades de atendimento de crianças com "distúrbio de aprendizagem", consideradas inaptas dentro do sistema educacional convencional. (...) No momento atual, à luz de pesquisas psicopedagógicas que vêm se desenvolvendo, inclusive no nosso meio, e de contribuições da área da psicologia, sociologia, antropologia, linguística, epistemologia, o campo da psicopedagogia passa por uma reformulação. De uma perspectiva puramente clínica e individual, busca-se uma compreensão mais integradora do fenômeno da aprendizagem e uma atuação de natureza mais preventiva. (KIGUEL apud BOSSA, 2000, p. 18)

Assim, o termo já foi inventado e assinala de forma simples e direta uma das mais profundas e importantes razões da produção de um conhecimento científico, a Psicopedagogia, que nasceu da necessidade de uma melhor compreensão do processo de aprendizagem, não se basta como aplicação da Psicologia à Pedagogia. ( ...) sendo assim, pode-se defini-lo como aplicação da psicologia experimental à pedagogia. (MACEDO apud BOSSA, 2000, p. 17)

Na concepção de Polity (2002), a pedagogia com enfoque construtivista com base no Construcionismo social elenca três fatores básicos do processo educacional: a interdisciplinaridade, a interacionalidade e o pensamento complexo conduzindo o educando para a prática da transformação social. A autora faz a relação entre as dificuldades do aluno a as dificuldades do professor no processo ensino-aprendizagem, interrelacionando-os, até mesmo, nos fracassos, Pois a Constituição Federal do Brasil assume como fundamental, dentre outros, o princípio da igualdade, quando reza no caput de seu artigo 5, que "todos são iguais perante a lei, sem distinção de qualquer natureza, garantindo-se aos brasileiros e aos estrangeiros, residentes no País, a inviolabilidade do direito à vida, à liberdade, à igualdade, à segurança e à propriedade", o mesmo mencionado por Aranha (2000), o principal valor que permeia, portanto, a ideia da inclusão é o configurado no princípio da igualdade, pilar fundamental de uma sociedade democrática e justa: a diversidade requer a peculiaridade de tratamentos, para que não se transforme em desigualdade social.

A Psicopedagogia, como área de aplicação, antecede o status de área de estudos, a qual tem procurado sistematizar um corpo teórico próprio, definir o seu objeto de estudo, delimitar o seu campo de 
atuação e, para isso, recorre à Psicologia, Psicanálise, Linguística, Fonoaudiologia, Medicina, Pedagogia (PORTO, 2009).

A Psicopedagogia, como área de aplicação, antecede o status de área de estudos, a qual tem procurado sistematizar um corpo teórico próprio, definir o seu objeto de estudo, delimitar o seu campo de atuação e, para isso, recorre à Psicologia, Psicanálise, Linguística, Fonoaudiologia, Medicina, Pedagogia (PORTO, 2009).

Desta forma, falar sobre psicopedagogia é, necessariamente, falar sobre articulação entre educação e psicologia, articulação essa que desafia estudiosos e práticos dessas duas áreas. Embora quase sempre presente no relato de inúmeros trabalhos científicos que tratam principalmente dos problemas ligados à aprendizagem, o termo psicopedagogia não consegue adquirir clareza na sua dimensão conceitual. (NEVES apud BOSSA, 2000, p. 18)

A afirmação de que a Psicopedagogia, historicamente, surgiu na fronteira entre a Psicologia e a Pedagogia merece maior atenção.

\begin{abstract}
Menciono as tentativas de explicação para o fracasso escolar por outras vias que não a pedagógica e a psicológica. (...) os fatores etiológicos utilizados para explicar índices alarmantes do fracasso escolar envolviam quase que exclusivamente fatores individuais, como desnutrição, problemas neurológicos, psicológicos, etc. (...) No Brasil, particularmente durante a década de 70, foi amplamente difundido o rótulo de Disfunção Cerebral Mínima para as crianças que apresentavam, como sintoma proeminente, distúrbios na escolaridade (KIGUEL apud BOSSA, 2000, pp. 18-19).
\end{abstract}

Assim, a Psicopedagogia se ocupa da aprendizagem humana, que adveio de uma demanda - o problema da aprendizagem, colocado em um território pouco explorado situado além dos limites da Psicologia e da própria Pedagogia - e evoluiu em virtude da existência de recursos, ainda que embrionários, para atender a essa demanda, constituindo-se, assim, em uma prática. Como se preocupa com o problema de aprendizagem, deve ocupar-se inicialmente do processo de aprendizagem. Portanto, vemos que Psicopedagogia estuda as características da aprendizagem humana: como se aprende, como essa aprendizagem varia evolutivamente e está condicionada por vários fatores, como se produzem as alterações na aprendizagem, como reconhecê-Ias, tratá-Ias e preveni-Ias (PORTO, 2009).

\title{
3 CONCLUSÃO
}

Para a realização deste artigo foi necessária uma revisão documental e bibliográfica sobre o tema abordado, apresentando conceitos sobre a Psicopedagogia. Sendo assim, para a definição do problema de pesquisa levou-se em consideração a expectativa de investigar a importância da Psicopedagogia nos processos de Ensino-Aprendizagem. O problema é expresso, então, pela questão: quais as competências da Psicopedagogia nos processos de Ensino- Aprendizagem? Tendo como objetivo geral: Apresentar conceitos importantes na área da Psicopedagogia nos processos de Ensino-aprendizagem e os objetivos 
específicos são: descrever conceitos sobre a Psicopedagogia; apresentar o profissional Psicopedagogo e por fim descrever a Psicopedagogia como uma junção da Pedagogia e Psicologia e outras ciências.

Os objetivos específicos foram alcançados tendo resultados devidamente demonstrado no segundo capítulo deste artigo. O alcance dos objetivos específicos foi favorável ao atendimento do objetivo geral, o qual foi apresentar conceitos importantes na área da Psicopedagogia nos processos de Ensino-aprendizagem sendo respondida a questão problema sendo apresentado no artigo as competências da Psicopedagogia nos processos de Ensino- Aprendizagem

Diante dos resultados apontados e por tratar-se de um estudo constituído de apenas pesquisa bibliográfica, pôde-se perceber que o artigo traz como limitação, a impossibilidade do levantamento da totalidade das pesquisas realizadas com relação ao tema principal que Psicopedagogia. Neste sentido, sugere-se a realização de novas pesquisas, desta vez de forma quantitativa ou qualitativa, por meio de questionários ou entrevista, com vistas a ampliar as análises dos resultados desta pesquisa em ambientes escolares e também em Instituições financeiras, a exemplo das Cooperativas de Crédito, avaliando a importância da Psicopedagogia nos processos de seleção, recrutamento e integração do contratado e na gestão do conhecimento dos profissionais, na busca pelo eficiência e eficácia da organização no mercado de atuação. 


\section{REFERÊNCIAS}

ARANHA, Maria Salete F. Inclusão social e municipalização (2000). Disponível em: http://cape.edunet.sp.gov.br/textos/textos/10.doc Acesso em: 21 fev. 2011.

BONALS, Joan; GONZÁLEZ, Ângela. A demanda por avaliação psicopedagógica. In: SÁNCHEZCANO, Manuel; BONALS, Joan. Avaliação psicopedagógica. Trad. Fátima Murad. Porto Alegre: Artmed, 2008.

BOSSA, Nadia A. A psicopedagogia no Brasil: contribuições a partir da prática. Porto Alegre: Artes Médicas, 2000.

CARVALHO, Maria. A trajetória da psicopedagogia, suas contribuições e limites. Disponível em: http://www.psicopedagoga.org/index.php?option=com_content\&view=frontpage\&Item id=1 Acesso em: 24 fev. 2011.

CHAMAT, L. S. J. A arte de cultivar. São Paulo: Vetar, 2005.

CHAMAT, L. S. J. Relações vinculares e Aprendizagem. São Paulo: Vetar Editora, 1996.

CHAMAT, Leila Sara José. Técnicas de intervenção psicopedagógica para dificuldades e problemas de aprendizagem. São Paulo: Vetor, 2008.

FERNANDÉZ, Alicia. O saber em jogo: a psicopedagogia possibilitando autorias de pensamento. Porto Alegre: Artmed, 2001.

MORAIS, Maria de Lourdes Cysneiros. Bases Conceituais para o Diagnóstico Psicopedagógico Institucional (2004). Disponível em:

http://www.abpp.com.br/artigos/51.htm Acesso em: 21 fev. 2011.

OKANO et al. Crianças com dificuldades escolares atendidas em programa de suporte psicopedagógico na escola: avaliação do autoconceito. São Paulo: PRC, 2003.

OLIVEIRA, Antonia Soares Silveira e. Educação inclusiva, utopia possível: uma leitura psicopedagógica de crianças/adolescentes com dificuldades de aprendizagem. Florianópolis: UFSC, 2001. (Dissertação de Mestrado).

PERES, M. R.; OLIVEIRA, M. H. M. A. Psicopedagogia - Limites e possibilidades a partir de relatos de profissionais. São Paulo: PUC, 2007.

POLITY, E. Dificuldade de Ensinagem. São Paulo: Vetor Editora, 2002.

PORTO, Olivia. Bases da Psicopedagogia: diagnóstico e intervenção nos problemas de aprendizagem. 4 ed. Rio de Janeiro: Wak, 2009.

REVISTA psicopedagogia $\mathrm{n}^{\circ} 14$ (32): 21-27, 1995;

SCOZ, Beatriz. Psicopedagogia e realidade escolar: o problema escolar e de aprendizagem. 2 ed. Petrópolis, RJ: Vozes. 1994. 
VERGARA, Sylvia Constant. Projeto e relatórios de pesquisa em administração. São Paulo: Atlas, 2005.

VISCA, Jorge. Clínica Psicopedagógica. Epistemologia convergente. Porto Alegre: Artes Médicas, 1987.

WEISS, Maria Lucia Lemme. Psicopedagogia clínica: uma visão diagnóstica. Porto Alegre: Artes Médicas, 2001. 